\title{
Comparative analysis of volatile and non-volatile flavor compounds in rice paste made by $\alpha$-amylase according to cultivars
}

\author{
Eun Young Son ${ }^{1} \cdot$ Hye Won Kim ${ }^{1} \cdot$ Sun Ah Kim ${ }^{1} \cdot$ Sang Mi Lee ${ }^{1} \cdot$ Se Hee Paek ${ }^{2}$.

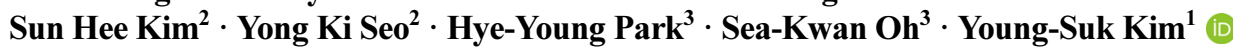

\section{$\alpha$-amylase를 이용하여 제조한 쌀 페이스트의 품종에 따른 휘발성비휘발성 향미성분 비교분석}

\author{
손은영 ${ }^{1}$ - 김혜 원 ${ }^{1}$ - 김선아 ${ }^{1}$ - 이상미 ${ }^{1}$ - 백세희 ${ }^{2}$ - 김선희 ${ }^{2}$ 서용기 ${ }^{2}$ •
}

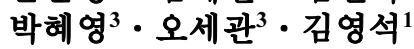

Received: 31 July 2017 / Accepted: 6 September 2017 / Published Online: 30 September 2017

(C) The Korean Society for Applied Biological Chemistry 2017

\begin{abstract}
Rice that the half of population in the world eats as a staple food is mostly produced and consumed in Asia. However, its consumption is nowadays decreasing mainly due to diet diversity. Accordingly, some attempts are in demand to enhance the utilization of rice. In this study, profiling of volatile and nonvolatile flavor components in rice pastes obtained by $\alpha$-amylase was performed and compared according to nine different rice cultivars domestically cultivated in Korea using gas chromatographymass spectrometry combined by solid phase microextraction and gas chromatography-time of flight-mass spectrometry after a derivatization, respectively. In total, 46 volatile compounds identified included 6 alcohols, 6 aldehydes, 4 esters, 4 furan derivatives, 4 ketones, 1 acid, 1 sulfur-containing compound, 7
\end{abstract}

Young-Suk Kim $(\bowtie)$

E-mail: yskim10@ewha.ac.kr

${ }^{1}$ Department of Food Science and Engineering, Ewha Womans University, Seoul 03760, Republic of Korea

${ }^{2}$ Food R\&D center, CJ Cheiljedang, Gyeonggi 16495, Republic of Korea

${ }^{3}$ Department of Central Area Crop Science, National Institute of Crop Science, Rural Development Administration, Suwon 16613, Republic of Korea

This is an Open Access article distributed under the terms of the Creative Commons Attribution Non-Commercial License (http://creativecommons. org/licenses/by-nc/3.0/) which permits unrestricted non-commercial use, distribution, and reproduction in any medium, provided the original work is properly cited. hydrocarbons, 5 aromatics and 8 terpenes. The non-volatile flavor components found were composed of 12 amino acids, 6 sugars and 4 sugar alcohols. In principal component analysis, rice paste samples could be discriminated according to cultivars on the score plots of volatile and non-volatile flavor compounds. In particular, some volatile compounds such as pentanal and 4,7-dimethylundecane could contribute to distinguish Senong 17 white and Senong 17 brown, whereas ethanol, 6-methylhep-5-en-2-one, and tridecane could be highly related to the discrimination of Iipum from other cultivars. Among non-volatile compounds, some amino acids such as glycine, serine and $\gamma$-aminobutyric acid and some sugars such as sucrose and fructose were mainly responsible for the discrimination of Danmi from the other cultivars. On the other hand, galactose, arabitol and mannose were more closely related to Senong 17 white than Senong 17 brown.

Keywords Amino acids $\cdot \alpha$-Amylase $\cdot$ Cultivars $\cdot$ Rice paste Sugars $\cdot$ Sugar alcohols $\cdot$ Volatile compounds

\section{서 론}

전세계 인구의 절반이 주식으로 하는 쌀은 대부분 아시아에서 생산소비되고 있다. 그러나 최근 국내에서는 식생활이 다양해지 면서 국민 1 인당 평균 쌀 소비량은 꾸준히 감소하고 있으며, 이 러한 경향은 앞으로도 지속될 것으로 예측된다. 이에 쌀의 소 
비를 증가시키기 위해 주식 이외에 쌀을 이용한 다양한 가공식 품의 개발이 필요한 상황이다(Kim 등, 2011). 또한 우리나라에 서 쌀 가공식품은 주로 떡류, 밥죽류, 주류, 면류 등에 편중되 어 있으며, 그 외 기타 과자류나 음료류 등으로도 이용 되고 있 다. 이에 더욱 다양화 되는 소비양상과 안전성, 편의성, 건강기 능성을 중시하는 소비자 요구에 부응하기 위해서는 다양하고 고 품질의 쌀 가공제품의 개발 및 쌀 가공산업의 활성화가 필요한 상황이다(Kim 2011).

쌀을 이용한 가공식품 개발 시 향미는 소비자 기호에 영향을 미치며(Goff와 Klee 2006), 이에 따라 원료 쌀의 향미와 관련 있는 휘발성 성분 및 비휘발성 성분을 분석하는 연구가 수행되 어 왔다. 쌀의 휘발성 성분에 대한 주요 연구 결과로는 조리된 쌀을 gas chromatography-mass spectrometry (GC-MS)와 gas chromatography-olfactometry로 분석하여 쌀의 향미성분을 밝혀 내고 이를 다변량 분석하여 구별되는 6 종의 쌀 향미성분 타입 을 분류한 연구(Yang 등, 2008)와 쌀의 조리단계에 따라 비휘 발성 성분들이 열 분해되어 생성되는 휘발성 성분을 분석한 연 구(Zeng 등, 2009)가 있었다. 비휘발성 성분에 대한 주요 연구 로는 쌀의 아미노산과 유기산, 당, 당알콜을 분석하고 이에 따 른 항산화능을 측정한 연구( $\operatorname{Kim}$ 등, 2014)와 gas chromatography-time of flight-mass spectrometry (GC-TOF-MS)로 흑미 6 종과 백미 1 종에 대하여 1 차 대사산물과 2 차 대사산물을 분석 하고 data mining process를 활용하여 이들의 상관관계를 밝히 는 연구도 보고되었다(Kim 등, 2013).

한편, 쌀 가공 시 효소 처리를 이용하여 가공효율을 높이는 연구들도 진행된 바 있다. 쌀로부터 미강유 추출시 $\alpha$-amylase 를 활용한 추출방법이 기존의 용매추출방법에 비해 $5 \%$ 정도 높은 추출 수율을 얻을 수 있었다(Hernandez 등, 2000). 또한 열에 안정한 $\alpha$-amylase 처리방법은 단백질 분리에 매우 효율적 이어서 단백질이 풍부한 쌀가루 생산에 유용하게 이용될 수 있 다(Shin과 Daigle 1997). 기타 효소 처리된 쌀은 백미보다 더 높은 항산화능을 가진다는 보고도 있었다(Das 등, 2008).

그러나 아직까지 효소를 처리하여 제조된 쌀 페이스트의 향 미 특성과 관련이 있는 휘발성성분 및 비휘발성 성분을 분석하 여 비교한 연구는 없었다. 따라서 본 연구에서는 국내에서 유 통되고 있는 서로 다른 품종별 효소 처리된 쌀 페이스트의 휘 발성 성분과 비휘발성 성분들을 기기분석하고, 다변량 통계분석 으로 시료 간의 차이를 규명하고자 하였다. 이는 쌀 페이스트 를 활용한 가공식품 개발을 위한 기초연구로 활용될 수 있을 것이다.

\section{재료 및 방법}

\section{재료}

원료 쌀 품종에 따른 9종의 쌀 페이스트 시료는 다음의 쌀 원 료를 이용하여 제조되었다. 실험에 사용된 쌀 원료의 품종은 일 품(IP), 고아미 4호(GO), 안다(AN), 다산 1호(DA), 설갱 $(\mathrm{SE})$, 단미(DN), 삼광 $(\mathrm{SM})$, 서농 17호 백미 $(\mathrm{GW})$, 서농 17호 현미 (GB)로 총 9종이었으며, Table 1에 각 품종의 재배지역과 생산 년도를 나타내었다. 실험에 사용된 쌀 원료는 모두 국내산으로 $\mathrm{IP}, \mathrm{GO}, \mathrm{AN}, \mathrm{DA}, \mathrm{SE}, \mathrm{DN}, \mathrm{SM}$ 은 경기도 수원시에서 재배한
Table 1 Cultivation region and year of rice cultivars

\begin{tabular}{ccc}
\hline \hline Rice Cultivars & Cultivation Region & Production Year \\
\hline Iipum(IP) & Suwon, Gyeonggi & 2014 \\
Goami 4(GO) & Suwon, Gyeonggi & 2014 \\
Anda(AN) & Suwon, Gyeonggi & 2014 \\
Dasan 1(DA) & Suwon, Gyeonggi & 2014 \\
Seolgang(SE) & Suwon, Gyeonggi & 2014 \\
Danmi(DN) & Suwon, Gyeonggi & 2014 \\
Samgwang (SM) & Suwon, Gyeonggi & 2014 \\
Senong 17 white(GW) & Jincheon, Chungbuk & 2014 \\
Senong 17 brown(GB) & Jincheon, Chungbuk & 2014 \\
\hline
\end{tabular}

것이며, $\mathrm{GW}$ 와 $\mathrm{GB}$ 는 충청북도 진천군에서 재배한 것이다. 모 든 쌀 원료는 2014년도에 수확한 것을 사용하였다.

\section{쌀 페이스트 제조}

쌀 페이스트는 위의 쌀 원료를 사용하여 다음과 같은 방법으로 제조하였다. 쌀 원료를 $55-60{ }^{\circ} \mathrm{C}$ 에서 1.5 시간 동안 증숙한 후, $60{ }^{\circ} \mathrm{C}$ 에서 2 시간동안 $0.15-0.2 \%$ 농도의 $\alpha$-amylase를 처리하였 다. 효소 처리된 쌀과 증류수는 35:65의 비율로 혼합하여 입자 크기 $50 \mu \mathrm{m}$ 이하가 되도록 습식 분쇄하였다. 이 후 100-150 $\mathrm{bar}$ 의 압력을 가해 가압균질화 하고, $98{ }^{\circ} \mathrm{C}$ 에서 30 초 동안 살 균하였다. 살균이 끝난 쌀 페이스트는 냉각 및 포장하여 보관 하였다.

\section{쌀 페이스트의 휘발성 성분 추출}

쌀 페이스트의 휘발성 성분은 solid phase microextraction (SPME)를 이용하여 추출하였다. 추출을 위해 $20 \mathrm{~mL}$ glass vial 에 쌀 페이스트 시료 $5 \mathrm{~g}$ 을 넣고 screw cap(Ultraclean $18 \mathrm{~mm}$, Agilent Technologies, Ratingen, Germany)으로 밀봉하였다. 밀 봉된 vial은 각각 $250 \mathrm{rpm}, 50^{\circ} \mathrm{C}$ 에서 30 분 동안 교반 및 평형시킨 후, 10 분간 CAR/PDMS/DVB SPME fiber (Supelco, Bellefonte, $\mathrm{PA}, \mathrm{USA}$ )를 사용하여 흡착하였다. Fiber에 흡착된 휘발성 성분 들은 $\mathrm{GC}$ 주입구 $\left(250{ }^{\circ} \mathrm{C}\right)$ 에서 5 분간 탈착하여 $\mathrm{GC}$ 칼럼으로 이 동시켰다.

\section{GC-MS를 이용한 쌀 페이스트의 휘발성 성분 분석}

$\mathrm{SPME}$ 에 의해 추출된 쌀 페이스트의 휘발성 성분은 $7890 \mathrm{~B} \mathrm{GC}$ system과 5977A mass selective detector (MSD, Agilent Technologies, Santa Clara, CA, USA)를 이용하여 분석하였다. 분석을 위한 칼럼으로는 $\mathrm{DB}-\mathrm{WAX}(30 \mathrm{~m}$ length $\times 0.25 \mathrm{~mm}$ I.D. $\times 0.25 \mu \mathrm{m}$ film thickness, J\&W Scientific, Folsom, CA, USA) 를 사용하였다. 오븐온도는 $40{ }^{\circ} \mathrm{C}$ 에서 6 분간 유지하였고, $150{ }^{\circ} \mathrm{C}$ 까지 $3{ }^{\circ} \mathrm{C} / \mathrm{min}$ 으로 증가시킨 후, 다시 $200^{\circ} \mathrm{C}$ 까지 $5{ }^{\circ} \mathrm{C} / \mathrm{min}$ 으로 올려주었다. 주입기 온도는 $250{ }^{\circ} \mathrm{C}$ 로, splitless mode에서 분석 하였으며, 이동상 기체로는 helium을 $0.8 \mathrm{~mL} / \mathrm{min}$ 의 유속으로 사 용하였다. MSD (Agilent 5977A) 조건은 EI ionization voltage $70 \mathrm{eV}$, mass range 35-350 a.m.u.로 설정하였다.

쌀 페이스트의 비휘발성 성분 추출 및 유도체화

시료를 falcon tube에 $0.05 \mathrm{~g}$ 씩 넣고 액체 질소에 담근 후 바로 
$80 \%$ methanol 용액 $10 \mathrm{~mL}$ 에서 30초간 vortex를 수행하였다. 이후 $70{ }^{\circ} \mathrm{C}$ 에서 25 분간 sonication (Branson, Danbury, CT, USA) 한 뒤, $4{ }^{\circ} \mathrm{C}, 3500 \mathrm{rpm}$ 에서 10 분간 원심분리(UNION 32R PLUS, Hanil Science Inc, Incheon, Korea) 하였다. 이후 상층 액 $100 \mu \mathrm{L}$ 을 chloroform $1 \mathrm{~mL}$ 에 첨가하여 30초간 vortex 한 뒤 동일하게 20 분간 sonication 시킨 후, 10 분간 원심분리를 수 행하였다. 상층액 $400 \mu \mathrm{L}$ 를 $1.5 \mathrm{~mL}$ safe lock tube (Eppendorf, Hamburg, Germany)에 담아 centri-vap (Labcono Co, Kanasas City, $\mathrm{MO}, \mathrm{USA}$ )에서 overnight하여 완전히 건조시켰다. 완전히 건조된 시료에 methoxyamine- $\mathrm{HCl}(20 \mathrm{mg} / \mathrm{mL}$ in pyridine) (Sigma-Aldrich, St. Louis, MO, USA)을 $50 \mu \mathrm{L}$ 넣고 $30{ }^{\circ} \mathrm{C}$ 에 서 90분 동안 반응시켰다. N,O-bis (trimethylsilyl) trifluoroacetamide (BSTFA) containing 1\% trimethylchlorosilane (Sigma-Aldrich) 을 $90 \mu \mathrm{L}$ 넣고 $70^{\circ} \mathrm{C}$ 에서 30 분간 추가로 반응시킨 뒤, insert가 들어간 $1.5 \mathrm{~mL}$ auto-sampler에 담아 GC-TOF-MS를 이용하여 분석하였다.

\section{GC-TOF-MS를 이용한 쌀 페이스트의 비휘발성 성분 분석}

쌀 페이스트의 비휘발성 아미노산, 당, 당알콜 분석에는 Agilent $6890 \mathrm{~N} \mathrm{GC}$ 에 연결된 TOF pegasus III MS (Leco, St. Joseph, MI, USA)를 이용하였다. 분석을 위한 칼럼으로는 DB5MS ( $30 \mathrm{~m}$ Length $\times 0.25 \mathrm{~mm}$ I.D. $\times 0.25 \mu \mathrm{m}$ film thickness, $\mathrm{J} \& \mathrm{~W}$ Scientific, Folsom, CA, USA)를 사용하였다. 오븐온도는 80 ${ }^{\circ} \mathrm{C}$ 에서 5 분간 유지시킨 후 $180{ }^{\circ} \mathrm{C}$ 까지 $10{ }^{\circ} \mathrm{C} / \mathrm{min}$ 으로 증가시켰 다. 그리고 $180^{\circ} \mathrm{C}$ 에서 5 분간 유지하였다가 $240{ }^{\circ} \mathrm{C}$ 까지 $5{ }^{\circ} \mathrm{C} /$ $\min$ 으로 다시 증가시켰다. 마지막으로 $240{ }^{\circ} \mathrm{C}$ 에서 5 분간 유지 시킨 후 $290{ }^{\circ} \mathrm{C}$ 까지 $10^{\circ} \mathrm{C} / \mathrm{min}$ 으로 증가시켜 10 분간 유지하였 다. 주입구의 온도는 $270{ }^{\circ} \mathrm{C}$ 였으며, splitless 모드로 설정하였다. 이동상 기체로는 helium을 $1.44 \mathrm{~mL} / \mathrm{min}$ 의 속도로 이용하였다. Mass scan range는 30-600 a.m.u.로, scan rate은 20 spectra/ $\sec$ 로 설정하였다.

\section{쌀 페이스트의 휘발성비휘발성 성분의 동정 및 정량}

$\mathrm{SPME}$ 를 이용하여 추출한 휘발성 성분의 동정은 mass spectral database (W9N08.L) 및 manual interpretation을 기반으로 수행 하였다. 또한 hexane에 용해시킨 saturated alkanes $\left(\mathrm{C}_{7}-\mathrm{C}_{17}\right.$, $100 \mu \mathrm{g} / \mathrm{mL}, w / \mathrm{v})$ 을 외부표준물질로 사용하여 각 휘발성 성분의 retention index (RI) value를 구한 후 문헌에서 보고된 RI 값과 비교하였다. GC-TOF-MS를 이용하여 분석한 비휘발성 성분의 동정은 fiehn, mainlib, wiley9, replibrary를 이용하여 수행하였 다. 휘발성 성분과 비휘발성 성분의 정량은 내부표준물질에 대 한 상대적인 peak area 값을 구하여 비교하였으며, 휘발성 성분 의 정량을 위한 내부표준물질로는 2-ethyl hexanol $(100 \mu \mathrm{g} / \mathrm{mL}$, $\mathrm{w} / \mathrm{v})$, 비휘발성 성분의 정량을 위한 내부표준물질로는 carbohydrates는 threitol $(100 \mu \mathrm{g} / \mathrm{mL}, \mathrm{w} / \mathrm{v}) 5 \mu \mathrm{L}$, amino acids는 norleucine $(100 \mu \mathrm{g} / \mathrm{mL}, \mathrm{w} / \mathrm{v}) 5 \mu \mathrm{L}$ 를 각각 사용하였다.

\section{통계분석}

원료 쌀의 품종에 따른 쌀 페이스트의 휘발성 성분 및 비휘발 성 차이를 파악하기 위하여 다변량 통계분석(SIMCA-P version 11.0, Umetric, Umea, Sweden)을 사용하여 주성분 분석(PCA, Principal component analysis)을 수행하였다. 또한 각각의 성분
에 대한 시료간의 유의적인 차이를 알아보기 위하여 statistical package for the social sciences(SPSS, version 12.0, Chicago, $\mathrm{IL}, \mathrm{USA}$ )를 이용하여 유의수준 $p<0.05$ 에서 분산분석(ANOVA, Analysis of variance)과 Duncan's multiple comparison test를 수행하였다.

\section{결과 및 고찰}

\section{효소 처리된 쌀 페이스트의 휘발성 성분 분석}

효소 처리된 쌀 페이스트에서 동정된 휘발성 성분을 Table 2에 나타내었다. 총 46 종의 휘발성 성분이 검출되었으며, 이에는 알 콜류 6종, 케톤류 4종, 벤젠류 5종, 알데히드류 6종, 퓨란류 4 종, 터핀류 8종, 에스터류 4종, 탄화수소류 7종, 황 함유 화합 물 1종, 산 1종이 포함되었다. 알콜류는 쌀에 주로 sweet, floral, fruity 향미특성을 부여하는데 영향을 미친다(Bryant와 McClung 2011). 6종의 알콜류 중 ethanol, pentan-1-ol, oct-1en-3-ol은 모든 품종에서 검출되었으나, ethanol의 함량은 IP와 $\mathrm{SM}$ 에서 유의적으로 높았다. 대표적인 퓨젤유 성분인 pentan-1ol은 지질 산화 생성물로 알려져 있으며(Champagne 등, 2005), $\mathrm{SE}$ 에서 가장 높았다. 버섯과 유사한 냄새특성을 가진 oct-1-en3-ol은 $\mathrm{GW}$ 에서 가장 높았고, 그 다음으로는 $\mathrm{DA}$ 와 $\mathrm{SE}$ 순서로 함량이 높았다. 이외의 알콜류 중 hexan-1-ol, hex-3-en-1-ol 및 butan-1-ol은 DN에서 가장 높았다. 4종의 케톤류 중 1-(3methylphenyl) ethanone은 $\mathrm{GB}$ 에서만 검출되었고, herbaceous, pungent한 향미특성(Morales 등, 2005)을 나타내는 6-methyl-5hepten-2-one은 IP에서 가장 높았다. 이에 비해 sweet하고 minty-camphoraceous 특성(Vaewta와 Siree 2006)을 가지는 cyclohexanone은 $\mathrm{SE}$ 와 $\mathrm{DN}$ 에서 높게 나타났다. 벤젠 고리를 가 진 aromatic compounds는 6종이 검출되었다. 1,4-xylene과 methyl benzene은 모든 품종에서 검출되었으며, 다른 품종들에 비해 $\mathrm{GW}$ 에서 함량이 높았다. Green, fresh향(Sawamura 등, 2004)을 가진 p-cymene은 SE에서 가장 높았다. Ethylbenzene은 $\mathrm{SM}$ 에서 가장 함량이 높았고, $\mathrm{GW}$ 와 $\mathrm{SE}$ 에서 그 뒤를 따랐다. 알데히드류는 6 종이 검출되었는데, 대부분 직쇄형 지방족 알데 히드류는 green, grassy, fatty한 향미특성을 나타내며, 주로 지 질의 산화에 의해 생성되는 것으로 알려져 있다(Yajima 등, 1978). Hexanal은 덜 익은 과일 냄새의 주 원인 물질로(Bryant 와 McClung 2011), GB보다 GW에서 약 11배 더 많은 양이 검출되었다. 특히 hexanal은 특유의 강한 풋내 및 산패취로 인 해 소비자에게 거부감을 일으킬 수 있는 성분이다(Yang 등, 2007). Nutty, sweet향과 관련된 pentanal(Yang 등, 2008)은 $\mathrm{GW}$ 에서 가장 높았다. Nonanal은 fresh, citrusy 한 냄새특성 (Sawamura 등, 2004)을 나타내며, $\mathrm{GW}$ 에서 가장 높았고 $\mathrm{DA}$ 와 $\mathrm{SE}$ 가 그 뒤를 따랐다. Fatty-fruity 향이 나며, 각각 0.7, 0.15, $13 \mathrm{ppb}$ 로 물에서 상대적으로 낮은 역치값을 가지는(Guadagni 등, 1963) octanal, 3-methyl-butanal 및 hept-2-enal도 검출되었다. 검출된 4종의 퓨란류 중 2-pentylfuran은 beany한 특성을 나타 내며, linoleic acid의 일중항 산소에 의한 산화나 가열에 의한 분해 기작에 의해 유래하는 것으로 알려져 있다(Lee 등, 2013). 이의 함량은 다른 품종에서 보다 $\mathrm{SE}$ 에서 높았다. $\mathrm{AN}, \mathrm{DA}$, $\mathrm{GW}$ 는 그 뒤를 따라 높았으며, 이 세 품종간에는 함량 차이가 
Table 2 Volatile compounds in enzyme treated rice samples according to cultivars

\begin{tabular}{|c|c|c|c|c|c|c|c|c|c|c|}
\hline \multirow{2}{*}{ Volatile compounds } & \multirow{2}{*}{$\mathrm{RI}^{1)}$} & \multicolumn{9}{|c|}{ Relative peak areas $\left.(\text { mean } \pm \mathrm{SD})^{2}\right)$} \\
\hline & & $\mathrm{IP}^{3)}$ & $\mathrm{GO}^{4)}$ & $\mathrm{AN}^{5)}$ & $\mathrm{DA}^{6)}$ & $\mathrm{SE}^{7)}$ & $\mathrm{DN}^{8)}$ & $\mathrm{SM}^{9)}$ & $\mathrm{GW}^{10)}$ & $\mathrm{GB}^{11)}$ \\
\hline \multicolumn{11}{|c|}{ Alcohols } \\
\hline Ethanol & 933 & $9.083 \pm 1.529^{\mathrm{a}}$ & $0.046 \pm 0.011^{\mathrm{c}}$ & $0.393 \pm 0.075^{\mathrm{c}}$ & $0.819 \pm 0.344^{\mathrm{c}}$ & $0.684 \pm 0.044^{c}$ & $0.203 \pm 0.059^{\mathrm{c}}$ & $4.622 \pm 0.407^{\mathrm{b}}$ & $0.527 \pm 0.098^{\mathrm{c}}$ & $0.274 \pm 0.075^{\mathrm{c}}$ \\
\hline Butan-1-ol & 1152 & N.D ${ }^{12)}$ & $0.008 \pm 0.001^{\mathrm{b}}$ & N.D & N.D & N.D & $2.748 \pm 0.016^{\mathrm{a}}$ & N.D & N.D & $0.019 \pm 0.001^{\mathrm{b}}$ \\
\hline Pentan-1-ol & 1251 & $0.123 \pm 0.017^{\mathrm{efg}}$ & $0.066 \pm 0.007^{\mathrm{g}}$ & $0.223 \pm 0.023^{\mathrm{bcd}}$ & $0.223 \pm 0.044^{\mathrm{bcd}}$ & $0.316 \pm 0.028^{\mathrm{a}}$ & $0.177 \pm 0.064^{\mathrm{def}}$ & $0.099 \pm 0.081^{\mathrm{fg}}$ & $0.287 \pm 0.055^{\mathrm{ab}}$ & $0.052 \pm 0.007^{\mathrm{g}}$ \\
\hline Hexan-1-ol & 1353 & $0.06 \pm 0.012^{\mathrm{b}}$ & $0.122 \pm 0.012^{\mathrm{b}}$ & N.D & $0.074 \pm 0.03^{\mathrm{b}}$ & $0.181 \pm 0.013^{\mathrm{b}}$ & $0.358 \pm 0.257^{\mathrm{a}}$ & $0.054 \pm 0.008^{\mathrm{b}}$ & N.D & $0.191 \pm 0.036^{\mathrm{b}}$ \\
\hline Hex-3-en-1-ol & 1382 & N.D & $0.004 \pm 0.002$ & N.D & N.D & N.D & $0.172 \pm 0.264$ & N.D & N.D & N.D \\
\hline Oct-1-en-3-ol & 1450 & $0.075 \pm 0.004^{\mathrm{d}}$ & $0.024 \pm 0.001^{\mathrm{e}}$ & $0.073 \pm 0.022^{\mathrm{d}}$ & $0.113 \pm 0.028^{\mathrm{b}}$ & $0.105 \pm 0.01^{\mathrm{bc}}$ & $0.092 \pm 0.009^{\mathrm{bcd}}$ & $0.08 \pm 0.008^{\mathrm{cd}}$ & $0.173 \pm 0.016^{\mathrm{a}}$ & $0.016 \pm 0.005^{\mathrm{e}}$ \\
\hline \multicolumn{11}{|c|}{ Aldehydes } \\
\hline Pentanal & 972 & $0.294 \pm 0.074^{\mathrm{ef}}$ & N.D & $1.181 \pm 0.251^{\mathrm{b}}$ & N.D & $0.163 \pm 0.006^{\mathrm{ef}}$ & $0.018 \pm 0.009^{\mathrm{f}}$ & $0.594 \pm 0.051^{\mathrm{cd}}$ & $1.817 \pm 0.385^{\mathrm{a}}$ & $0.131 \pm 0.016^{\mathrm{ef}}$ \\
\hline 3-Metyhl-butanal & 972 & N.D & $0.109 \pm 0.031^{\mathrm{b}}$ & N.D & N.D & $1.414 \pm 0.081^{\mathrm{a}}$ & $0.086 \pm 0.043^{\mathrm{b}}$ & N.D & N.D & $0.028 \pm 0.008^{\mathrm{b}}$ \\
\hline Hexanal & 1075 & $1.729 \pm 0.009^{\mathrm{de}}$ & $1.08 \pm 0.14^{\mathrm{de}}$ & $3.165 \pm 0.213^{\mathrm{c}}$ & $3.373 \pm 0.851^{\mathrm{cb}}$ & $4.487 \pm 0.15^{\mathrm{b}}$ & $2.106 \pm 0.788^{\mathrm{cd}}$ & $3.206 \pm 0.421^{\mathrm{c}}$ & $5.785 \pm 1.33^{\mathrm{a}}$ & $0.52 \pm 0.427^{\mathrm{e}}$ \\
\hline Octanal & 1281 & $0.094 \pm 0.028^{\mathrm{bc}}$ & $0.024 \pm 0.002^{\mathrm{d}}$ & $0.116 \pm 0.014^{\mathrm{b}}$ & $0.106 \pm 0.046^{\mathrm{b}}$ & N.D & $0.188 \pm 0.017^{\mathrm{a}}$ & N.D & $0.185 \pm 0.027^{\mathrm{a}}$ & $0.047 \pm 0.002$ \\
\hline Hept-2-enal & 1314 & N.D & N.D & N.D & N.D & $0.053 \pm 0.005$ & N.D & N.D & $0.073 \pm 0.014$ & N.D \\
\hline Nonanal & 1386 & $0.232 \pm 0.03^{\mathrm{de}}$ & $0.06 \pm 0.004^{\mathrm{fg}}$ & $0.284 \pm 0.034^{\text {cde }}$ & $0.409 \pm 0.083^{\mathrm{abc}}$ & $0.453 \pm 0.027^{\mathrm{ab}}$ & $0.32 \pm 0.272^{\mathrm{bcd}}$ & $0.296 \pm 0.012^{\text {bcde }}$ & $0.493 \pm 0.03^{\mathrm{a}}$ & $0.032 \pm 0.023^{\mathrm{g}}$ \\
\hline \multicolumn{11}{|c|}{ Esters } \\
\hline Ethyl propionate & 951 & N.D & N.D & N.D & N.D & N.D & N.D & N.D & N.D & $0.007 \pm 0.004$ \\
\hline $\begin{array}{l}\text { (2-Ethyl-3-hydroxyhexy) 2- } \\
\text { methylpropanoate }\end{array}$ & 1868 & N.D & $0.003 \pm 0.001^{\mathrm{b}}$ & N.D & $0.034 \pm 0.019^{\mathrm{glb}}$ & $0.02 \pm 0.009^{\mathrm{b}}$ & $0.005 \pm 0.001^{\mathrm{b}}$ & N.D & N.D & $0.072 \pm 0.007^{\mathrm{b}}$ \\
\hline $\begin{array}{l}\text { 2,2,4-Trimethyl-3- } \\
\text { carboxyisopropylisobutyl } \\
\text { pentanoate }\end{array}$ & 2000 & $0.025 \pm 0.008^{\mathrm{b}}$ & $0.009 \pm 0.002^{\mathrm{b}}$ & $0.036 \pm 0.014^{\mathrm{b}}$ & $0.03 \pm 0.014^{\mathrm{b}}$ & $0.023 \pm 0.004^{\mathrm{b}}$ & N.D & N.D & $0.031 \pm 0.006^{\mathrm{b}}$ & $0.173 \pm 0.006^{\mathrm{b}}$ \\
\hline \multicolumn{11}{|c|}{ Furans } \\
\hline 2-Ethylfuran & 945 & N.D & $0.007 \pm 0.002^{\mathrm{c}}$ & $0.102 \pm 0.017^{\mathrm{b}}$ & $0.248 \pm 0.079^{\mathrm{a}}$ & $0.198 \pm 0.013^{\mathrm{a}}$ & $0.046 \pm 0.008^{\mathrm{bc}}$ & N.D & $0.185 \pm 0.084^{\mathrm{a}}$ & $0.014 \pm 0.007^{\mathrm{c}}$ \\
\hline 2-Propylfuran & 1028 & N.D & N.D & N.D & $0.06 \pm 0.023$ & $0.097 \pm 0.005$ & N.D & N.D & N.D & N.D \\
\hline 2-Butyllfuran & 1120 & N.D & $0.012 \pm 0.002^{\mathrm{c}}$ & N.D & $0.252 \pm 0.087^{\mathrm{ab}}$ & $0.282 \pm 0.088^{\mathrm{ab}}$ & $0.121 \pm 0.027^{\mathrm{bc}}$ & N.D & N.D & $0.007 \pm 0.002^{\mathrm{c}}$ \\
\hline 2-Pentylfuran & 1223 & $0.487 \pm 0.065^{\mathrm{e}}$ & N.D & $3.172 \pm 0.459^{\mathrm{c}}$ & $3.351 \pm 0.379^{c}$ & $4.91 \pm 0.306^{\mathrm{b}}$ & $1.049 \pm 0.167^{\mathrm{e}}$ & $0.929 \pm 0.134^{\mathrm{e}}$ & $3.164 \pm 0.905^{\mathrm{c}}$ & $0.08 \pm 0.011^{\mathrm{e}}$ \\
\hline \multicolumn{11}{|c|}{ Ketones } \\
\hline 4-Methyl-heptan-2-one & 1198 & N.D & N.D & $0.09 \pm 0.004^{\mathrm{a}}$ & $0.085 \pm 0.019^{\mathrm{a}}$ & $0.119 \pm 0.019^{\mathrm{a}}$ & $0.014 \pm 0.005^{\mathrm{b}}$ & N.D & $0.118 \pm 0.03^{\mathrm{a}}$ & N.D \\
\hline Cyclohexanone & 1277 & N.D & N.D & N.D & $0.071 \pm 0.022^{\mathrm{bc}}$ & $0.217 \pm 0.013^{\mathrm{a}}$ & $0.113 \pm 0.075^{\mathrm{b}}$ & N.D & N.D & N.D \\
\hline 6-Methylhep-5-en-2-one & 1330 & $0.115 \pm 0.011^{\mathrm{a}}$ & $0.008 \pm 0.001^{\mathrm{d}}$ & N.D & N.D & $0.027 \pm 0.012^{\mathrm{c}}$ & $0.021 \pm 0.001^{\mathrm{cd}}$ & $0.053 \pm 0.006^{\mathrm{b}}$ & N.D & $0.017 \pm 0.007^{\mathrm{cd}}$ \\
\hline 1-(3-Methylphenyl) ethanone & 1675 & N.D & N.D & N.D & N.D & N.D & N.D & N.D & N.D & $0.012 \pm 0.001$ \\
\hline \multicolumn{11}{|c|}{ Acids } \\
\hline $\begin{array}{l}\text { 2-Hydroxy-2-(3-hydroxyphenyl) } \\
\text { acetic acid }\end{array}$ & 1174 & $2.652 \pm 0.411^{\mathrm{b}}$ & N.D & $8.133 \pm 5.696^{\mathrm{g}}$ & N.D & $4.467 \pm 0.361^{\mathrm{g}}$ & $0.058 \pm 0.572^{\mathrm{g}}$ & $2.409 \pm 0.29^{g}$ & $8.108 \pm 2.265^{\mathrm{g}}$ & $1.002 \pm 0.338^{\mathrm{g}}$ \\
\hline
\end{tabular}




\begin{tabular}{|c|c|c|c|c|c|c|c|c|c|c|}
\hline \multirow{2}{*}{ Volatile compounds } & \multirow{2}{*}{$\mathrm{RI}^{1)}$} & \multicolumn{9}{|c|}{ " Relative peak areas $(\text { mean } \pm \mathrm{SD})^{2)}$} \\
\hline & & $\mathrm{IP}^{3)}$ & $\mathrm{GO}^{4)}$ & $\mathrm{AN}^{5)}$ & $\mathrm{DA}^{6)}$ & $\mathrm{SE}^{7)}$ & $\mathrm{DN}^{8)}$ & $\mathrm{SM}^{9)}$ & $\mathrm{GW}^{10)}$ & $\mathrm{GB}^{11)}$ \\
\hline \multicolumn{11}{|c|}{ Sulfur-containing Compounds } \\
\hline Dimethyl disulfide & 1064 & $0.016 \pm 0.001$ & N.D & $0.07 \pm 0.017$ & N.D & N.D & N.D & N.D & $0.106 \pm 0.015$ & N.D \\
\hline \multicolumn{11}{|c|}{ Hydrocarbons } \\
\hline 4-Ethyl-2-methylhexa-2,3-diene & & N.D & N.D & N.D & N.D & N.D & N.D & N.D & N.D & $0.025 \pm 0.024$ \\
\hline Octane & 801 & $0.127 \pm 0.034^{\mathrm{d}}$ & $0.008 \pm 0.003^{\mathrm{d}}$ & $0.917 \pm 0.181^{\mathrm{b}}$ & $0.839 \pm 0.375^{\mathrm{b}}$ & $1.422 \pm 0.05^{\mathrm{a}}$ & $0.075 \pm 0.004^{\mathrm{d}}$ & $0.211 \pm 0.015^{\mathrm{d}}$ & $0.966 \pm 0.164^{\mathrm{b}}$ & N.D \\
\hline 2,4-Dimethyl-1-heptene & 878 & $0.125 \pm 0.023^{\mathrm{b}}$ & N.D & $1.035 \pm 0.251^{\mathrm{a}}$ & $1.063 \pm 0.545^{\mathrm{a}}$ & $0.935 \pm 0.756^{\mathrm{a}}$ & $0.115 \pm 0.028^{\mathrm{b}}$ & $0.634 \pm 0.048^{\mathrm{ab}}$ & $0.877 \pm 0.359^{\mathrm{a}}$ & N.D \\
\hline 2,2,4,6,6-Pentamethylheptane & 951 & $0.187 \pm 0.076^{\text {ef }}$ & $0.026 \pm 0.007^{\mathrm{f}}$ & $0.856 \pm 0.161^{\mathrm{ab}}$ & $0.878 \pm 0.336^{\mathrm{ab}}$ & $1.039 \pm 0.095^{\mathrm{a}}$ & $0.326 \pm 0.052^{\mathrm{de}}$ & $0.783 \pm 0.04^{\mathrm{b}}$ & $0.689 \pm 0.065^{\mathrm{bc}}$ & N.D \\
\hline 4,7-Dimethylundecane & 998 & N.D & N.D & $0.084 \pm 0.06$ & N.D & N.D & N.D & $0.035 \pm 0.014$ & $0.099 \pm 0.042$ & N.D \\
\hline Tridecane & 1292 & $0.113 \pm 0.021$ & N.D & N.D & N.D & N.D & N.D & N.D & N.D & N.D \\
\hline $\begin{array}{l}\text { (3E)-3-Ethyl-2-methyl-1,3- } \\
\text { hexadiene }\end{array}$ & 1405 & N.D & $0.012 \pm 0.004^{\mathrm{e}}$ & $0.039 \pm 0.007^{\mathrm{d}}$ & N.D & $0.105 \pm 0.01^{\mathrm{a}}$ & N.D & N.D & $0.075 \pm 0.002^{\mathrm{b}}$ & N.D \\
\hline \multicolumn{11}{|c|}{ Benzenes } \\
\hline Methylbenzene & 1032 & $1.177 \pm 0.216^{\mathrm{cde}}$ & $0.1 \pm 0.017^{\mathrm{e}}$ & $2.416 \pm 0.470^{\mathrm{ab}}$ & $2.788 \pm 0.991^{\mathrm{ab}}$ & $3.062 \pm 0.173^{\mathrm{ab}}$ & $0.739 \pm 0.133^{\mathrm{de}}$ & $3.375 \pm 0.698^{\mathrm{a}}$ & $3.931 \pm 1.205^{\mathrm{a}}$ & $0.045 \pm 0.021^{\mathrm{e}}$ \\
\hline Ethylbenzne & 1113 & $1.249 \pm 0.095^{\mathrm{ef}}$ & $0.093 \pm 0.028^{\mathrm{g}}$ & $2.957 \pm 0.342^{\mathrm{cd}}$ & N.D & $3.69 \pm 0.453^{\mathrm{bc}}$ & $0.929 \pm 0.233^{\mathrm{fg}}$ & $5.465 \pm 1.098^{\mathrm{a}}$ & $4.465 \pm 1.042^{\mathrm{ab}}$ & $0.036 \pm 0.005^{\mathrm{g}}$ \\
\hline 1,4-Xylene & 1121 & $0.117 \pm 0.023^{\mathrm{f}}$ & $0.038 \pm 0.008^{\mathrm{f}}$ & $1.071 \pm 0.066^{\mathrm{cd}}$ & $1.373 \pm 0.244^{\mathrm{bc}}$ & $1.6 \pm 0.172^{\mathrm{abc}}$ & $0.118 \pm 0.049^{f}$ & $1.279 \pm 0.253^{\mathrm{bcd}}$ & $1.743 \pm 0.661^{\mathrm{ab}}$ & $0.021 \pm 0.007^{\mathrm{f}}$ \\
\hline Styrene & 1246 & $0.048 \pm 0.014^{\mathrm{cd}}$ & $0.002 \pm 0.001^{\mathrm{e}}$ & $0.062 \pm 0.019^{\mathrm{bc}}$ & $0.105 \pm 0.012^{\mathrm{ab}}$ & $0.101 \pm 0.013^{\mathrm{ab}}$ & $0.013 \pm 0.006^{\mathrm{de}}$ & $0.12 \pm 0.066^{\mathrm{a}}$ & $0.123 \pm 0.003^{\mathrm{a}}$ & N.D \\
\hline 1,4-Bis(1,1-dimethylethyl) benzene & 1421 & N.D & N.D & N.D & $0.08 \pm 0.007^{\mathrm{ab}}$ & $0.132 \pm 0.007^{\mathrm{a}}$ & N.D & N.D & N.D & N.D \\
\hline \multicolumn{11}{|c|}{ Terpenes } \\
\hline$\alpha$-Pinene & 1015 & $0.292 \pm 0.037^{\mathrm{b}}$ & N.D & N.D & $0.289 \pm 0.211^{\mathrm{b}}$ & N.D & N.D & $0.221 \pm 0.086^{\mathrm{b}}$ & N.D & N.D \\
\hline Camphene & 1055 & $0.569 \pm 0.108^{\mathrm{a}}$ & N.D & N.D & $0.05 \pm 0.016^{\mathrm{c}}$ & $0.048 \pm 0.006^{\mathrm{c}}$ & $0.006 \pm 0.002^{\mathrm{c}}$ & $0.246 \pm 0.024^{\mathrm{b}}$ & N.D & N.D \\
\hline$\alpha$-Phellandrene & 1149 & $0.073 \pm 0.011$ & N.D & N.D & N.D & N.D & N.D & N.D & N.D & N.D \\
\hline dl-Limonene & 1184 & $0.246 \pm 0.008^{\mathrm{cd}}$ & $0.013 \pm 0.004^{\mathrm{e}}$ & $0.415 \pm 0.033^{\mathrm{b}}$ & $0.573 \pm 0.043^{\mathrm{a}}$ & $0.422 \pm 0.039^{\mathrm{b}}$ & $0.058 \pm 0.051^{\mathrm{e}}$ & $0.131 \pm 0.018^{\mathrm{de}}$ & $0.307 \pm 0.219^{\text {bc }}$ & $0.014 \pm 0.01^{\mathrm{e}}$ \\
\hline$\beta$-Phellandrene & 1193 & N.D & N.D & N.D & N.D & $0.071 \pm 0.012$ & N.D & N.D & N.D & N.D \\
\hline$p$-Cymene & 1259 & $0.041 \pm 0.015^{\mathrm{bc}}$ & N.D & $0.029 \pm 0.014^{\mathrm{bcd}}$ & $0.05 \pm 0.007^{\mathrm{ab}}$ & $0.073 \pm 0.032^{\mathrm{a}}$ & $0.006 \pm 0.003^{\mathrm{d}}$ & $0.043 \pm 0.012^{\mathrm{bc}}$ & N.D & N.D \\
\hline 2 - $\beta$-Pinene & 1330 & $0.035 \pm 0.004^{\mathrm{b}}$ & N.D & N.D & $0.115 \pm 0.032^{\mathrm{b}}$ & $0.101 \pm 0.009^{\mathrm{b}}$ & $0.024 \pm 0.006^{\mathrm{b}}$ & $0.093 \pm 0.016^{\mathrm{b}}$ & $0.087 \pm 0.056^{\mathrm{b}}$ & N.D \\
\hline$\alpha$-Copaene & 1481 & N.D & N.D & $0.032 \pm 0.007$ & N.D & N.D & N.D & N.D & N.D & N.D \\
\hline
\end{tabular}

${ }^{2)}$ Mean values of relative peak area to that of internal standard \pm standard deviation

${ }^{3}$ Rice paste made by lipum

${ }^{4)}$ Rice paste made by Goami 4

${ }^{5}$ Rice paste made by Anda

${ }^{6}$ Rice paste made by Dasan 1

Rice paste made by Seolgan

${ }^{8)}$ Rice paste made by Danmi

${ }^{9}$ Rice paste made by Samgwang

${ }^{10}$ Rice paste made by Senong 17 white

${ }^{11)}$ Rice paste made by Senong 17 brown

${ }^{12}$ Not detected 
크지 않았다. 2-ethylfuran은 다른 품종들에서 보다 DA에서 가 장 높았으며, 2-butylfuran과 2-propylfuran은 $\mathrm{SE}$ 에서 가장 함량 이 높았다. 7종의 터핀류 중 orange-like fruity향을 내는 dllimonene (Kelebek과 Selli 2011)은 모든 품종에서 검출되었으 며, 그 함량은 $\mathrm{DA}, \mathrm{SE}, \mathrm{AN}$ 에서 높게 나타났다. 식품첨가물로 자주 사용되는 camphene은 herbal 향을 내는데(Sawamura 등, 2004), IP에서 현저하게 높았다. Pine-like향과 관련 있는 $\alpha$ pinene과 green, fresh 향과 관련 있는 2- $\beta$-pinene도 검출되었는 데(Sawamura 등, 2004), 대부분 품종에서 매우 낮은 수준으로 발견이 되었고 시료간에도 큰 차이가 없었다. 또한 freshness와 관련이 있는 $\alpha$-phellandrene과 $\beta$-phellandrene은 각각 IP와 $\mathrm{SE}$ 에서만 검출되었다. Spicy향을 내는 $\alpha$-copaene (Miyazawa 등, 2016)은 AN에서만 검출되었다. 에스터류 중 시료간의 유의적인 차이가 있는 것은 ethyl 3-methyl butanoate와 ethyl propionate 이었다. 강한 fruity향(Schieberle과 Hofmann 1997)과 관련이 있 는 ethyl 3-methyl butanoate은 $\mathrm{DN}$ 에서만 검출되었고, fruity, rum과 유사한 향미특성을 가진 ethyl propionate(Kanwar 등, 2005)는 $\mathrm{GB}$ 에서만 검출되었다.

한편 검출된 7종의 탄화수소류 대부분은 쌀의 향미 특성에 큰 영향을 주지 않는 것으로 알려져 있다(Elaine 등, 2005). 이 중 4,7-dimethylundecane은 품종간에 유의적인 차이는 없었으며, 4-ethyl-2-methyl hexa-2,3-diene은 GB에서만 검출되었다. 본 연 구에서 유일하게 검출된 황 함유 성분인 dimethyl disulfide는 황을 함유한 아미노산의 분해산물로서 마늘향과 유사한 특성을 주며(Wright 등, 2006), 우유에서 산화에 의해 생성되는 대표적 인 이취성분으로 보고된 바 있다(Jung 등, 1998).

\section{효소 처리된 쌀 페이스트의 비휘발성 성분 분석}

효소 처리된 쌀 페이스트에서 동정된 아미노산, 당류 및 당알 콜 성분들을 Table 3 에 나타내었다. 총 12 종의 아미노산 및 아 미노산 유도체인 alanine (Ala), valine (Val), leucine (Leu), proline (Pro), glycine (Gly), serine (Ser), threonine (Thr), aspartic acid (Asp), glutamine (Gln), $\gamma$-aminobutyric acid (GABA), glutamic acid (Glu), asparagine (Asn)이 동정되었다. 아미노산 성분들은 쌀의 감칠맛, 단맛 및 쓴맛 등에 영향을 미 치며, Strecker 분해반응 및 지질의 자동산화에 의해 쌀 및 쌀 가공식품의 주요 휘발성 성분들 생성에 영향을 미친다 (Karahadian과 Johnson 1995). 동정된 아미노산들 중 Asp는 조 리된 쌀의 sweetness와 palatability에 영향을 미칠 수 있는 것으 로 알려져 있다( $\mathrm{Kim}$ 등, 2014). 그 함량은 $\mathrm{GO}$ 에서 가장 높았 다. 감칠맛 성분으로 널리 알려져 있는 $\mathrm{Glu}$ 는 $\mathrm{DN}$ 에서 가장 높 았으며, glutamate decarboxylase의 작용에 의해 Glu에서 생성 되는 $\mathrm{GABA}$ 는 항고혈압의 활성을 나타내는 것으로 보고되고 있다(Baek 등, 2010). GABA는 $\mathrm{Glu}$ 가 가장 높았던 $\mathrm{DN}$ 에서 가 장 높게 나타났고, $\mathrm{GB}, \mathrm{GW}$ 가 근소한 차이로 그 뒤를 따랐다. $\mathrm{GABA}$ 가 서농 17 호인 $\mathrm{GB}$ 와 $\mathrm{GW}$ 에서 높게 나타나는 것은 서 농 17호가 다른 쌀 품종들에 비해 쌀겨 및 배젖 등에 아미노 산과 같은 영양성분들이 상대적으로 높은 함량으로 함유되어 있 기 때문이라고 볼 수 있다. Ala, Val, Leu, Gly, Ser은 다른 품 종에서 보다 $\mathrm{DN}$ 에서 가장 높았으며, Pro의 함량은 $\mathrm{DN}$ 과 $\mathrm{GB}$ 에서 높았다. Pro는 익힌 쌀의 주요 향미성분인 2-acetyl-1pyrroline의 전구체로도 알려져 있으며, 2-acetyl-1-pyrolline은 팝
콘(Schieberle 1991), corn tortilla (Karahadian과 Johnson 1995) 등에서 주요 향기활성성분으로도 밝혀져 있다. 이는 매우 낮은 역치값 및 특유의 향미특성으로 익힌 쌀 및 쌀 가공품의 품질 에 중요한 인자로 작용할 수 있다(Yoshihashi 등, 2002). 단맛을 부여하며 곡물의 제한 아미노산으로 알려져 있는 $\mathrm{Thr}$ 는 모든 품종에서 유의적인 차이는 없었다. 이에 비해 $\mathrm{Gln}$ 와 $\mathrm{Asn}$ 은 각 각 $\mathrm{SE}$ 와 $\mathrm{GO}$ 에서만 검출되었다. 또한, 당류 및 당알콜류로는 총 6종의 당류 fructose (Fru), mannose (Man), glucose (Glc), galactose (Gal), sucrose (Suc), maltose와 4종의 당알콜류 dithio-erythritol (Dit), arabitol (Ara), ribitol, myo-inositol (Myo)이 동정되었다. 당류는 단맛과 깊은 관련이 있는 것은 물론, 당 분해반응 및 Maillard 반응을 통해서 휘발성 성분 생성에도 관여할 수 있다 (Demyttenaere 등, 2002). 단맛은 조리된 쌀의 palatability에 크 게 영향을 미치는 특성이며, 당류 중 특히 Glu와 Suc가 중요한 역할을 한다(Tran 등, 2005). 이러한 당류들은 $\alpha$-amylase에 의 해 전분의 $\alpha-1,4$ glycosidic 결합이 분해되면서 Glc, dextrins, limit dextrins이 생성되는 작용에 의한 것이다(Gupta 등, 2003). $\mathrm{Glc}$ 의 함량은 $\mathrm{AN}$ 에서 가장 높았지만, 상대적으로 더 높은 단 맛을 가지는 $\mathrm{Fru}$ 와 Suc는 DN에서 가장 높았다. Erythrose로부 터 유래한 Dit는 GO에서 가장 높았다. Myo는 cyclohexane의 탄소마다 수소 원자 하나가 hydroxy기로 치환된 당알콜로서 사 람의 세포 성장에 필수적인 성장 인자로 알려져 있으며(Eagle 등, 1957), $\mathrm{DN}$ 에서 가장 높게 나타났다.

품종별 쌀 페이스트의 휘발성비휘발성 성분의 주성분 분석(PCA) 품종에 따라 효소 처리된 쌀 페이스트의 휘발성 성분들과 아미 노산, 당류 및 당알콜 등의 비휘발성 성분들에 근거한 PCA 분 석 결과를 Fig. 1과 Fig. 2에 나타내었다. 휘발성 성분의 경우, 제 1 주성분(PC1)은 $37.1 \%$, 제 2주성분(PC2)은 $15.3 \%$ 의 설명력 을 나타내어 총 변동의 $52.4 \%$ 를 설명하였다. $\mathrm{DA}, \mathrm{SE}, \mathrm{AN}$, $\mathrm{GW}$ 는 $\mathrm{PC} 1$ 에 의해 다른 품종들과 구분되고( $37.1 \%), \mathrm{GB}$ 는 $\mathrm{GW}$ 와 $\mathrm{PC} 2$ 에 의해 구분되었다(15.3\%). PCA loading plot (Fig. 2A)에서 pentanal, 4,7-dimethylundecane, dimethyl disulfide 같 은 성분들은 $\mathrm{GW}$ 의 특징으로 나타났고, butan-1-ol, ethyl propionate, 1-(3-methylphenyl) ethanone 같은 성분들은 $\mathrm{GB}$ 의 특징으로 나타났다. 이들 성분들이 $\mathrm{GB}$ 와 $\mathrm{GW}$ 를 구분하는데 관 련이 있는 성분들임을 알 수 있었다. 또한, IP가 다른 품종들과 구별되는 것은 주로 ethanol, 6-methylhep-5-en-2-one, camphene, $\alpha$-phellandrene, tridecane 같은 성분들에서 기인하는 것으로 나 타났다. SE의 경우, 3-methyl-1-butanal, 2-propylfuran, $\beta$ phellandrene, 1,4-Bis(1,1-dimethylethyl) benzene이 다른 품종들 과 구별되게 하는 성분들이었다. Hex-3-en-1-ol, ethyl 3methylbutanoate는 $\mathrm{DN}$ 과 관련 있는 휘발성 성분들이었다. $\mathrm{SM}$ 은 $\alpha$-pinene, $\mathrm{AN}$ 은 octanal, $\alpha$-copaene 같은 성분들이 향미에 영향을 미치는 성분들이었다. 비휘발성 성분의 $\mathrm{PCA}$ 분석 결과 로는 제 1 주성분 $(\mathrm{PC} 1)$ 은 $49.8 \%$, 제 2 주성분 $(\mathrm{PC} 2)$ 은 $17.0 \%$ 의 설명력을 나타내어 총 변동의 $66.8 \%$ 를 설명하였다. PCA score plot (Fig. 2A)에 따라 $\mathrm{DN}, \mathrm{GO}, \mathrm{GB}$ 는 $\mathrm{PC} 1$ 에 의해 다른 품종 들로부터 구별되었다(49.8\%). $\mathrm{GW}$ 는 $\mathrm{PC} 2$ 에 의해 $\mathrm{GB}$ 와 구별되 었다(17.0\%). PCA loading plot (Fig. 2B)에서 Gly, Ser, GABA, $\mathrm{Suc}, \mathrm{Fru}$ 같은 성분들이 주로 $\mathrm{DN}$ 과 다른 품종간에 차이를 보 이는데 기여한 것으로 나타났다. Gal, Ara, Man는 GB에 비해 
Table 3 Non-volatile compounds in enzyme treated rice samples according to cultivars

\begin{tabular}{|c|c|c|c|c|c|c|c|c|c|c|}
\hline \multirow{2}{*}{ Non-volatile compounds } & \multirow{2}{*}{$\mathrm{RT}^{1)}$} & \multicolumn{9}{|c|}{ " Relative peak areas $(\text { mean } \pm \mathrm{SD})^{2)}$} \\
\hline & & $\mathrm{IP}^{3)}$ & $\mathrm{GO}^{4)}$ & $\mathrm{AN}^{5)}$ & $\mathrm{DA}^{6)}$ & $\mathrm{SE}^{7)}$ & $\mathrm{DN}^{8)}$ & $\mathrm{SM}^{9)}$ & $\mathrm{GW}^{10)}$ & $\mathrm{GB}^{11)}$ \\
\hline \multicolumn{11}{|c|}{ Amino acids } \\
\hline Alanine & $07: 38$ & $0.047 \pm 0.012^{\mathrm{g}}$ & $0.135 \pm 0.003^{\mathrm{c}}$ & $0.043 \pm 0.004^{\mathrm{g}}$ & $0.048 \pm 0.007^{\mathrm{g}}$ & $0.085 \pm 0.06^{\mathrm{e}}$ & $0.263 \pm 0.017^{\mathrm{a}}$ & $0.066 \pm 0.003^{\mathrm{f}}$ & $0.129 \pm 0.008^{\mathrm{cd}}$ & $0.239 \pm 0.003^{\mathrm{b}}$ \\
\hline Valine & 09:43 & $0.006 \pm 0.001^{\mathrm{e}}$ & $0.027 \pm 0.005^{\mathrm{c}}$ & $0.017 \pm 0.003^{\mathrm{d}}$ & $0.012 \pm 0.002^{\mathrm{de}}$ & N.D ${ }^{12)}$ & $0.066 \pm 0.006^{\mathrm{a}}$ & N.D & $0.026 \pm 0.003^{c}$ & $0.049 \pm 0.002^{\mathrm{b}}$ \\
\hline Leucine & $10: 58$ & N.D & $0.009 \pm 0.001^{\mathrm{d}}$ & N.D & N.D & N.D & $0.03 \pm 0.003^{\mathrm{a}}$ & N.D & $0.012 \pm 0.002^{\mathrm{c}}$ & $0.022 \pm 0.001^{\mathrm{b}}$ \\
\hline Proline & $11: 00$ & N.D & $0.055 \pm 0.002^{\mathrm{b}}$ & $0.008 \pm 0.003^{\mathrm{a}}$ & N.D & N.D & $0.067 \pm 0.006^{\mathrm{a}}$ & $0.008 \pm 0.001^{\mathrm{d}}$ & $0.021 \pm 0.005^{\mathrm{c}}$ & $0.068 \pm 0.006^{\mathrm{a}}$ \\
\hline Glycine & 11:09 & $0.008 \pm 0.000^{\mathrm{d}}$ & $0.019 \pm 0.007^{\mathrm{cd}}$ & $0.019 \pm 0.007^{\mathrm{cd}}$ & $0.011 \pm 0.006^{\mathrm{d}}$ & $0.023 \pm 0.02^{\mathrm{cd}}$ & $0.088 \pm 0.014^{\mathrm{a}}$ & $0.015 \pm 0.003^{\text {cd }}$ & $0.044 \pm 0.008^{\mathrm{b}}$ & $0.024 \pm 0.001^{\mathrm{cd}}$ \\
\hline Serine & $11: 59$ & $0.012 \pm 0.002^{\mathrm{de}}$ & $0.041 \pm 0.004^{\mathrm{b}}$ & $0.019 \pm 0.003^{\text {cde }}$ & $0.029 \pm 0.011^{\mathrm{bc}}$ & $0.014 \pm 0.004^{\mathrm{de}}$ & $0.081 \pm 0.011^{\mathrm{a}}$ & $0.009 \pm 0.001^{\mathrm{e}}$ & $0.032 \pm 0.009^{\mathrm{bc}}$ & $0.039 \pm 0.003^{\mathrm{b}}$ \\
\hline Threonine & $12: 21$ & $0.018 \pm 0.027^{\mathrm{a}}$ & $0.006 \pm 0.000^{\mathrm{a}}$ & $0.004 \pm 0.000^{\mathrm{a}}$ & $0.005 \pm 0.002^{\mathrm{a}}$ & N.D & $0.016 \pm 0.002^{\mathrm{a}}$ & N.D & $0.009 \pm 0.001^{\mathrm{a}}$ & $0.013 \pm 0.001^{\mathrm{a}}$ \\
\hline Aspartic acid & 14:08 & $0.029 \pm 0.019^{\mathrm{cd}}$ & $0.077 \pm 0.002^{\mathrm{a}}$ & $0.009 \pm 0.001^{\mathrm{ef}}$ & $0.037 \pm 0.013^{\mathrm{bc}}$ & $0.033 \pm 0.007^{\mathrm{c}}$ & $0.069 \pm 0.005^{\mathrm{a}}$ & $0.009 \pm 0.001^{\mathrm{ef}}$ & $0.018 \pm 0.005^{\mathrm{de}}$ & $0.047 \pm 0.004^{\mathrm{b}}$ \\
\hline Glutamine & 14:09 & N.D & N.D & N.D & N.D & $0.029 \pm 0.007$ & N.D & N.D & N.D & N.D \\
\hline$\gamma$-Aminobutyric acid & $14: 15$ & $0.011 \pm 0.004^{\text {ef }}$ & $0.065 \pm 0.01^{\mathrm{d}}$ & $0.009 \pm 0.002^{\mathrm{f}}$ & $0.007 \pm 0.002^{\mathrm{f}}$ & $0.02 \pm 0.012^{\text {ef }}$ & $0.18 \pm 0.01^{\mathrm{a}}$ & $0.011 \pm 0.003^{\text {ef }}$ & $0.115 \pm 0.005^{\mathrm{c}}$ & $0.132 \pm 0.015^{\mathrm{b}}$ \\
\hline Glutamic acid & $15: 23$ & $0.013 \pm 0.003^{\mathrm{c}}$ & $0.009 \pm 0.000^{\mathrm{c}}$ & N.D & N.D & N.D & $0.02 \pm 0.001^{\mathrm{b}}$ & $0.003 \pm 0.000^{\mathrm{d}}$ & $0.003 \pm 0.001^{\mathrm{d}}$ & $0.009 \pm 0.002^{\mathrm{c}}$ \\
\hline Asparagine & 16:05 & N.D & $0.017 \pm 0.006$ & N.D & N.D & N.D & N.D & N.D & N.D & N.D \\
\hline \multicolumn{11}{|c|}{ Sugars and Sugar alcohols } \\
\hline Dithioerythritol & 09:11 & $0.121 \pm 0.004^{\mathrm{b}}$ & $0.19 \pm 0.008^{\mathrm{a}}$ & $0.118 \pm 0.049^{b}$ & $0.141 \pm 0.021^{\mathrm{b}}$ & $0.073 \pm 0.008^{\mathrm{c}}$ & $0.084 \pm 0.003^{\mathrm{c}}$ & $0.082 \pm 0.005^{\mathrm{c}}$ & N.D & $0.153 \pm 0.001^{\mathrm{b}}$ \\
\hline Arabitol & $14: 41$ & $0.027 \pm 0.003^{\mathrm{b}}$ & $0.013 \pm 0.002^{\mathrm{b}}$ & $0.017 \pm 0.002^{\mathrm{b}}$ & $0.019 \pm 0.002^{\mathrm{b}}$ & $0.021 \pm 0.003^{\mathrm{b}}$ & $0.027 \pm 0.002^{\mathrm{b}}$ & $0.028 \pm 0.001^{\mathrm{b}}$ & $0.058 \pm 0.037^{\mathrm{a}}$ & $0.007 \pm 0.001^{\mathrm{b}}$ \\
\hline Ribitol & $15: 26$ & $0.031 \pm 0.001^{\mathrm{bc}}$ & $0.055 \pm 0.054^{\mathrm{bc}}$ & $0.13 \pm 0.004^{\mathrm{a}}$ & $0.029 \pm 0.003^{\mathrm{c}}$ & $0.059 \pm 0.053^{\mathrm{b}}$ & $0.025 \pm 0.005^{\mathrm{bc}}$ & $0.039 \pm 0.003^{\mathrm{bc}}$ & $0.061 \pm 0.022^{\mathrm{b}}$ & $0.013 \pm 0.002^{\mathrm{c}}$ \\
\hline Fructose & $20: 16$ & $0.338 \pm 0.059^{j}$ & $1.064 \pm 0.029^{\mathrm{e}}$ & $0.669 \pm 0.003^{\mathrm{g}}$ & $0.574 \pm 0.040^{\mathrm{h}}$ & $1.361 \pm 0.031^{\mathrm{c}}$ & $2.567 \pm 0.062^{\mathrm{a}}$ & $0.481 \pm 0.245^{\mathrm{hi}}$ & $1.182 \pm 0.032^{\mathrm{d}}$ & $1.817 \pm 0.024^{\mathrm{b}}$ \\
\hline Mannose & 21:01 & $24.166 \pm 2.552^{\mathrm{cd}}$ & $29.703 \pm 0.578^{b}$ & $25.438 \pm 2.160^{\mathrm{cd}}$ & $26.921 \pm 2.253^{\mathrm{bcd}}$ & $22.919 \pm 2.823^{\mathrm{d}}$ & $26.658 \pm 2.056^{\mathrm{bcd}}$ & $23.852 \pm 2.293^{\mathrm{cd}}$ & $26.882 \pm 0.979^{\mathrm{bc}}$ & $6.898 \pm 0.277^{\mathrm{e}}$ \\
\hline Glucose & $21: 26$ & $11.647 \pm 1.284^{\mathrm{d}}$ & $6.88 \pm 0.166^{\mathrm{e}}$ & $19.019 \pm 1.117^{\mathrm{a}}$ & $15.398 \pm 0.937^{\mathrm{c}}$ & $17.275 \pm 0.256^{\mathrm{b}}$ & $11.873 \pm 0.242^{\mathrm{d}}$ & $12.724 \pm 0.818^{\mathrm{d}}$ & $17.406 \pm 0.140^{\mathrm{b}}$ & $1.133 \pm 0.072^{\mathrm{f}}$ \\
\hline Galactose & $22: 46$ & $0.231 \pm 0.039^{\mathrm{d}}$ & $0.088 \pm 0.003^{\mathrm{e}}$ & $0.356 \pm 0.019^{\mathrm{b}}$ & $0.264 \pm 0.034^{\mathrm{cd}}$ & $0.106 \pm 0.088^{\mathrm{e}}$ & $0.436 \pm 0.013^{\mathrm{a}}$ & $0.254 \pm 0.024^{\mathrm{cd}}$ & $0.204 \pm 0.050^{\mathrm{d}}$ & $0.013 \pm 0.002^{\mathrm{f}}$ \\
\hline myo-Inositol & $24: 38$ & $0.095 \pm 0.002^{\mathrm{d}}$ & $0.15 \pm 0.003^{\mathrm{b}}$ & $0.064 \pm 0.008^{\mathrm{ef}}$ & $0.05 \pm 0.008^{\mathrm{g}}$ & $0.102 \pm 0.007^{\mathrm{cd}}$ & $0.23 \pm 0.009^{\mathrm{a}}$ & $0.058 \pm 0.004^{\mathrm{efg}}$ & $0.11 \pm 0.006^{\mathrm{c}}$ & $0.155 \pm 0.012^{\mathrm{b}}$ \\
\hline Sucrose & $33: 47$ & $1.207 \pm 0.101^{\mathrm{fg}}$ & $6.974 \pm 0.084^{\mathrm{b}}$ & $1.062 \pm 0.060^{\mathrm{fgh}}$ & $1.332 \pm 0.043^{\mathrm{f}}$ & $1.853 \pm 0.051^{\mathrm{e}}$ & $16.837 \pm 0.286^{\mathrm{a}}$ & $0.766 \pm 0.055^{\mathrm{h}}$ & $3.498 \pm 0.716^{\mathrm{d}}$ & $6.260 \pm 0.433^{\mathrm{c}}$ \\
\hline Maltose & $35: 26$ & $28.527 \pm 3.873^{\text {cde }}$ & $26.14 \pm 0.256^{\mathrm{e}}$ & $41.336 \pm 2.973^{\mathrm{a}}$ & $32.173 \pm 3.822^{\mathrm{bcd}}$ & $34.297 \pm 0.844^{b}$ & $27.132 \pm 0.609^{\mathrm{de}}$ & $30.774 \pm 1.315^{\mathrm{cde}}$ & $32.926 \pm 5.284^{\mathrm{bc}}$ & $6.443 \pm 0.256^{\mathrm{f}}$ \\
\hline
\end{tabular}

${ }^{11}$ Retention index

${ }^{2)}$ Mean values of relative peak area to that of internal standard \pm standard deviation

${ }^{3)}$ Rice paste made by lipum

${ }^{4)}$ Rice paste made by Goami

${ }^{5}$ Rice paste made by Anda

${ }^{6)}$ Rice paste made by Dasan 1

T) Rice paste made by Seolgang

${ }^{8}$ Rice paste made by Danmi

${ }^{9}$ Rice paste made by Samgwang

${ }^{10)}$ Rice paste made by Senong 17 white

Rice paste made by Senong 17 brown

${ }^{2)}$ Not detected 
(A)
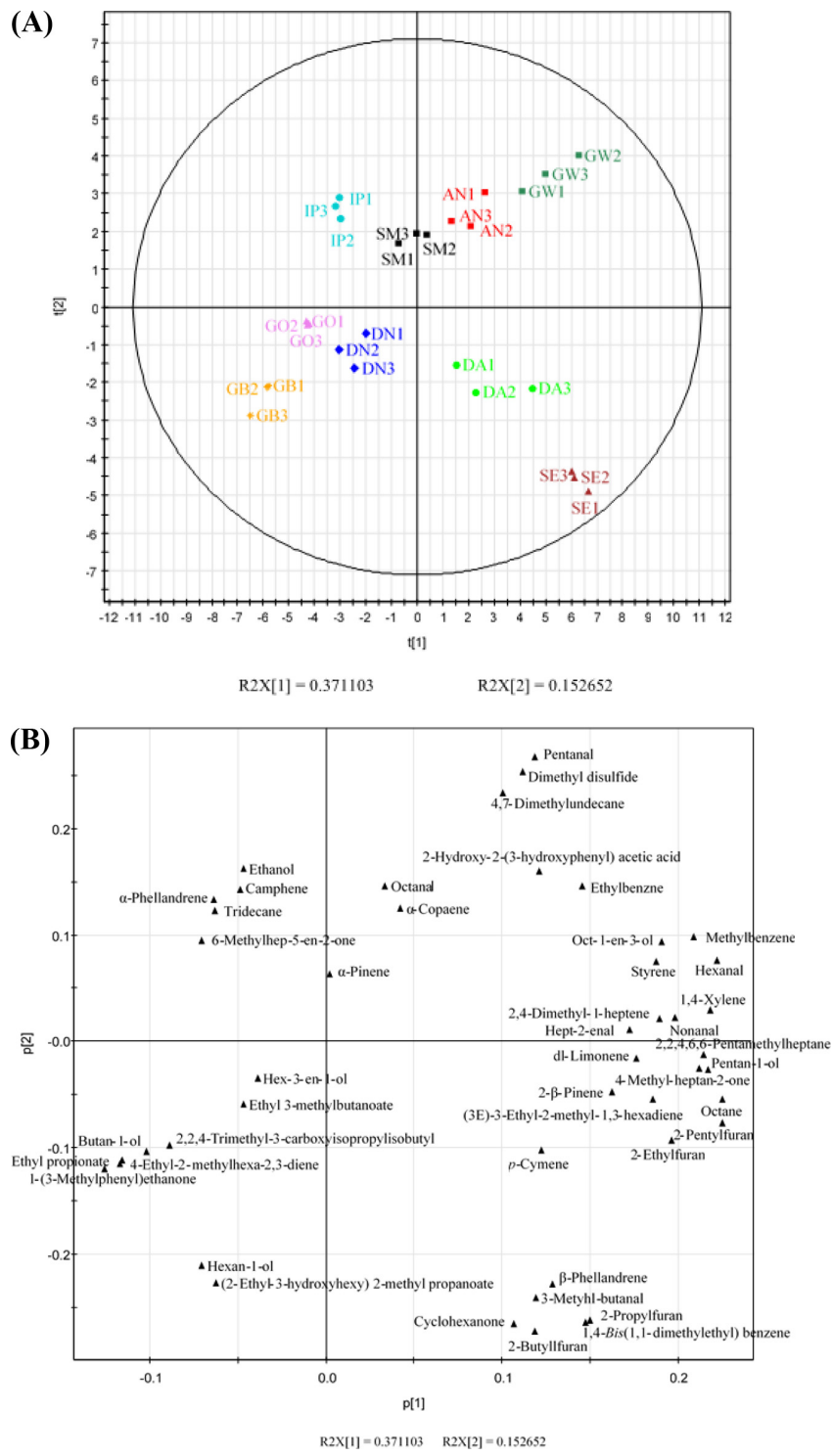

Fig. 1 Score plot (A) and loading plot (B) of volatile compounds according to cultivars (IP, Ilpum; GO, Goami 4; AN, Anda; DA, Dasan 1; SE, Seolgang; DN, Danmi; SM, Samgwang; GW, Senong 17 white; GB, Senong 17 brown)

$\mathrm{GW}$ 와 관련이 높은 것으로 나타났다. $\mathrm{GO}$ 의 경우 $\mathrm{Asn}, \mathrm{Asp}$, $\mathrm{Thr}$ 같은 성분들이 향미에 영향을 미치는 비휘발성 성분들이었다.

효소 처리된 다양한 품종의 쌀 페이스트의 향미 특성과 관련 이 있는 휘발성 성분 및 비휘발성 성분들을 $\mathrm{GC}-\mathrm{MS}$ 와 GCTOF-MS의 기기분석법과 다변량 통계 분석법을 이용하여 비교 하였다. 서로 다른 시료간의 차이와 특성을 밝힐 수 있었으며, 이에 관여하는 주요 성분들도 규명하였다. 쌀 가공제품 개발 및 향미특성 연구는 오늘날 제한적으로 이루어지고 있는데, 이의 발전을 위해서는 쌀 원료 자체에 대한 특성 연구가 선행되어야 한다. 이러한 연구 결과를 바탕으로 쌀의 품종별 특성을 고려 한 원료를 개발함으로써 쌀 페이스트의 원료로서의 가치 및 활 용도를 높이고 완제품의 품질력 향상 및 제품경쟁력을 확보하 는데 기여할 수 있다. 이에 쌀 가공식품의 새로운 시장 개척에
(A)
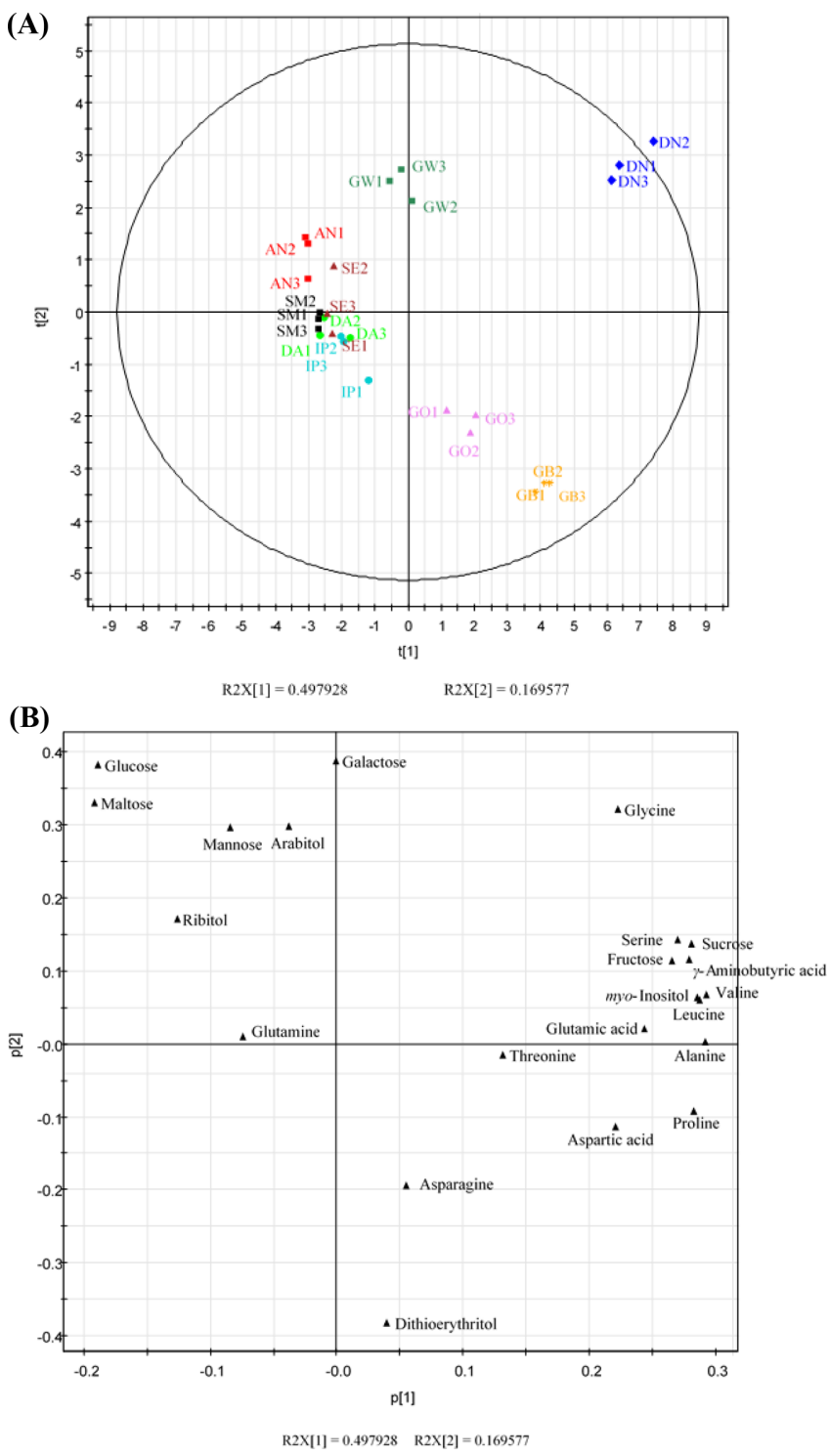

Fig. 2 Score plot (A) and loading plot (B) of non-volatile compounds according to cultivar (IP, Ilpum; GO, Goami 4; AN, Anda; DA, Dasan 1; SE, Seolgang; DN, Danmi; SM, Samgwang; GW, Senong 17 white; GB, Senong 17 brown)

이바지하고 새로운 쌀 수요 창출 및 쌀 산업의 활성화가 기대 된다.

\section{초 록}

쌀은 전세계 인구의 절반이 주식으로 사용하고 있으며, 대부분 아시아에서 생산되고 소비되고 있다. 그러나 최근 식생활이 다 양해지면서 쌀 소비량은 감소하고 있는 추세이다. 이에 쌀의 활 용도를 높이기 위한 다양한 시도가 요구되고 있다. 본 연구에 서는 $\alpha$-amylase로 처리된 9종의 서로 다른 품종의 쌀 페이스트 를 고체상 미세추출법과 가스 크로마토그래피-질량분석법을 이 용하여 휘발성 성분들을 프로파일링하고, 아미노산, 당류 및 당 
알콜 등의 비휘발성 향미성분들은 유도체화 처리 후 가스 크로 마토그래피-시간 비행형-질량분석법을 이용하여 비교분석을 수 행하였다. 총 46 종의 휘발성 성분들이 검출되었으며, 이에는 6 종의 알콜류, 6 종의 알데히드류, 4종의 에스터류, 4종의 퓨란 류, 4 종의 케톤류, 1 종의 산, 1 종의 황 함유 성분, 7 종의 탄화 수소류, 5 종의 벤젠류 및 8종의 터핀류 등을 포함되어 있다. 비 휘발성 향미성분들에는 12 종의 아미노산, 6 종의 당, 4 종의 당알 콜이 동정되었다. 휘발성 및 비휘발성 향미성분 분석에 근거한 주성분분석에 의해 서로 다른 쌀 페이스트 시료들을 구분할 수 있었다. 휘발성 성분의 경우 pentanal과 4,7-dimethylundecane는 서농 17 호 백미와 서농 17 호 현미를 구분 짓는 성분이었으며, 이에 비해 일품은 다른 품종들과 달리 ethanol, 6-methylhep-5en-2-one, tridecane과 같은 성분에서 차이를 보였다. 비휘발성 성분의 경우 glycine, serine, $\gamma$-aminobutyric acid 같은 아미노 산들과 sucrose, fructose 같은 당류가 다른 품종들과 단미를 구 분 짓는데 기여하는 성분이었다. 한편, galactose, arabitol, mannose는 서농 17호 현미에 비해 서농 17호 백미와 관련이 높은 성분들이었다.

Keywords 당 - 당알콜 - 쌀 페이스트 - 아미노산 - 품종 - 휘발 성 성분 $\cdot \alpha$-amylase

감사의 글 본 연구는 농촌진흥청의 농업공동연구 $\mathrm{FTA}$ 대응경쟁력향상기 술개발 식량작물경쟁력제고사업(PJ011550062017, 수출용 음료개발 및 제품 화)의 지원을 받아 수행되었습니다.

\section{References}

Baek JG, Shin SM, Kwon DY, Choi HK, Lee CH, Kim YS (2010) Metabolite profiling of Chenggukjang, a fermeted soybean paste, inoculated with various Bacillus strains during fermentation. Biosci Biotechnol Biochem 74(9): 1860-1868

Bryant RJ, McClung AM (2011) Volatile profiles of aromatic and nonaromatic rice cultivars using SPME/GC-MS. Food Chem 124: 501-513

Champagne ET, Bett-Garber KL, Thompson J, Mutters R, Grimm CC, McClung AM (2005) Effects of drain and harvest dates on rice sensory and physicochemical properties. Cereal Chem 82(4): 369-374

Das M, Banerjee R, Bal S (2008) Evaluation of physicochemical properties of enzyme treated brown rice (Part B). J Food Sci Technol 41(10): 2092 2096

Demyttenaere J, Tehrani KA, Kimpe N De (2002) The chemistry of the most important maillard flavor compounds of bread and cooked rice. ACS Symp Ser 826: 150-165

Eagle H, Oyama VI, Levy M, Freeman AE (1957) myo-Inositol as an essential growth factor for normal and malignant human cells in tissue culture. J Biol Chem 266: 191-205

Elaine TC, Karen L. BG, James T, Randall M, Casey CG, Anna MM (2005) Effects of Drain and Harvest Dates on Rice Sensory and Physicochemical Properties. Cereal Chem 82(4): 369-374

Goff SA, Klee HJ (2006) Plant volatile compounds: sensory cues for health and nutritional value? Science 311: 815-819

Guadagni DG, Buttery RG, Okano S (1963) Odour thresholds of some organic compounds associated with food flavours. J Sci Food Agric 14: 761-765

Gupta R, Gigras P, Mohapatra H, Goswami VK, Chauhan B (2003) Microbial $\alpha$-amylases: a biotechnological perspective. Process Biochem 38: 1599 1616

Hernandez N, Rodriguez-Alegría ME, Gonzalez F, Lopez-Munguia A (2000) Enzymatic treatment of rice bran to improve processing. J Am Oil Chem Soc 77(2): $177-180$
Jung MY, Yoon SH, Lee HO, Min DB (1998) Singlet oxygen and ascorbic acid effects on dimethyl disulfide and off-flavor in skim milk exposed to light. J Food Sci 63(3): 408-412

Kanwar SS, Verma HK, Kaushal RK, Gupta R, Chimni SS, Kumar Y, Chauhan GS (2005) Effect of solvents and kinetic parameters on synthesis of ethyl propionate catalysed by poly (AAc-co-HPMA-clMBAm)-matrix-immobilized lipase of Pseudomonas Aeruginosa BTS-2. World J Microbiol Biotechnol 21: 1037-1044

Karahadian C, Johnson KA (1995) Analysis of headspace volatiles and sensory characteristics of fresh corn tortillas made from fresh masa dough and spray-dried masa flour. J Agric Food Chem 41: 791-799

Kim DC, Choi JW, IN MJ (2011) Utilization of Leuconostoc mesenteroides 310-12 strain in the fermentation of a traditional Korean rice-based beverage. Appl Biol Chem 54(1): 21-25

Kim MR (2011) The Statue of Korea's rice industry and the rice processing industry. Food Ind Nutr 16(1): 22-26

Kim GR, Jung ES, Lee S, Lim SH, Lee CH (2014) Combined mass spectrometry-based metabolite profiling of different pigmented rice (Oryza sativa L.) seeds and correlation with antioxidant. Molecules 19(10): 15673-15686

Kim JK, Park SY, Lim SH, Yeo YS, Cho HS, Ha SH (2013) Comparative metabolic profiling of pigmented rice (Oryza sativa L.) cultivars reveals primary metabolites are correlated with secondary metabolites. J Cereal Sci 57: $14-20$

Kelebek H, Selli S (2011) Determination of volatile, phenolic, organic acid and sugar components in a Turkish cv. Dortyol(Citrus sinensis L.Osbeck) orange juice. J Sci Food Agric 91: 1855-1862

Miyazawa M, Yoshinaga S, Kashima Y, Nakahashi H, Hara N, Nakagawa H, Usami A (2016) Chemical composition and characteristic odor compounds in essential oil from Alismatis Rhizoma (Tubers of Alisma orientale). J Oleo Sci 65(1): 91-97

Morales MT, Luna G, Aparicio R (2005) Comparative study of virgin olive oil sensory defects. J Food Chem 91(2): 239-301

Sawamura M, Tu NTM, Onishi Y, Ogawa E, Choi HS (2004) Charcteristic odor components of Citrus reticulata Blanco(Ponkan) cold-preseed oil. Biosci Biothehnol Biochem 68(8): 1690-1697

Schieberle P (1991) Primary odorants of popcorn. J Agric Food Chem 39, $1141-1144$

Schieberle P, Hofmann T (1997) Evaluation of the character impact odorants in fresh strawberry juice by quantitative measurements and sensory studies on model mixtures. J Agric Food Chem 45: 227-232

Shin FF, Daigle K (1997) Use of enzymes for the separation of protein from rice flour. Cereal Chem 74(4): 437-441

Tran TU, Suzuki K, Odadome H, Ikezaki H, Homma S, Ohtsubo K (2005) Detection of changes in taste of japonica and indica brown and milled rice (Oryza sativa L.) during storage using physicochemical analyses and a taste sensing system. J Agric Food Chem 53(4): 1108-1118

Vaewta C, Siree C (2006) Free Amino Acid and Reducing Sugar Composition of Pandan (Pandanus amaryllifolius) Leaves. J Nat Sci 40: 67-74

Wright JM, Carunchia Whetstine ME, Evan Miracle R, Drake Maryanne (2006) Characterization of a cabbage off-flavor in whey protein isolate. J Food Sci 71(2): 86-90

Yajima I, Yanai T, Nakamura M, Sakakibara H, Habu T (1978) Volatile flavor components of cooked rice. Agric Biol Chem 42(6): 1229-1233

Yang DS, Shewfelt RL, Lee KS, Kays SJ (2008) Comparison of odor-active compounds from six distinctly rice flavor types. J Agric Food Chem 56(8): 2780-2787

Yoshihashi T, Huong NTT, Inatomi H (2002) Precursors of 2-Acetyl-1pyrroline, a potent flavor compound of an aromatic rice variety. J Agric Food Chem 50: 2001-2004

Zeng Z, Zhang H, Zhang T, Tamogami S, Chen JY (2009) Analysis of flavor volatiles of glutinous rice during cooking by combined gas chromatography-mass spectrometry with modified headspace solid-phase microextraction method. J Food Compost Anal 22: 347-353 